\title{
State of Forest and Rangeland Soils Research in the United States
}

\author{
Dan Binkley, Daniel D. Richter, Richard V. Pouyat, \\ and Linda H. Geiser
}

\section{Overview}

Flying across the eastern United States at an altitude of $10,000 \mathrm{~m}$, we see a landscape below that is a mosaic of forests, rivers, farm fields, towns, and cities. Almost all of the lands covered by forests today have undergone intensive harvest, and even regrowth and reharvests, following decades or centuries of cultivation-based agriculture and other land uses. The visible change in the boundaries of forests and fields is matched by similar, though less visible, patterns in the soils. Indeed, the soils that form the living surface of the Earth below may be as different on each side of the airplane as they are from one corner of the United States to another. Local differences in hillslopes and valley bottoms, in the types of bedrocks and sediments that sit below the living soil, and in the history of human land uses, may be greater than the differences driven by the climate of, for example, Virginia versus Oregon. The inhabitants of the land that became the United States survived on food and resources which were fundamentally derived from soils. The economic output of the colonies and the youthful United States flowed more from agriculture than from industry until at least the Civil War era (Gallman and Weiss 1969). Wood from the forests built the towns and cities, while energy

\section{Binkley $(\bowtie)$}

School of Forestry, Northern Arizona University,

Flagstaff, AZ, USA

e-mail: Dan.binkley@alumni.ubc.ca

\section{D. Richter}

Nicholas School of the Environment, Duke University, Durham, NC, USA

R. V. Pouyat

Northern Research Station, USDA Forest Service, Newark, DE, USA

\section{H. Geiser}

Washington Office, U.S. Department of Agriculture, Forest

Service, Washington, DC, USA from wood was the primary fuel of the American economy until the 1880s (U.S. Energy Information Administration 2011).

As we glide down to an altitude of $1000 \mathrm{~m}$ above the Sumter National Forest, near Union, SC, the tops of trees come into focus. These trees rise from soils formed over millions of years from the original granitic gneiss bedrock that underlies much of the Southeast. The soils were shaped by chemical and physical processes, largely mediated by the plants, animals, and microorganisms that form the biological engines of soil formation, weathering, and change. In the millennia before the arrival of the settlers, oaks (Quercus spp.), hickories (Carya spp.), and southern pines (Pinus spp., such as shortleaf [P. echinata]) shaped the soils that provisioned the first peoples - and further back in time, spruce (Picea spp.), fir (Abies spp.), and northern pines (e.g., eastern white pine [Pinus strobus]) graced the landscapes. After 1800, fields of cotton (Gossypium hirsutum) and other row crops and farm animals replaced almost all the forests, leading to soil degradation from massive erosion but also soil enrichment through liming and fertilization.

The economic depression of the 1930s brought changes to the soils of the Sumter National Forest, as agricultural abandonment was followed by reforestation with pine trees, either seeding in naturally or planted, to restore the fertility of soils. The Calhoun Experimental Forest was established in the 1940s to provide information that land managers would need to foster the regeneration of forests and forest soils across the entire southeastern region. The history of the soils of the Sumter National Forest entailed very large changes across decades, a century, or two centuries, against the backdrop of ongoing soil-forming processes on the timescale of millions of years. Some of the changes in the Sumter's soils may be unique. But if we glided down to any other landscape, we would find soils that, like the Sumter's, have been shaped by both natural and human factors. The unique histories of all forest soils across the United States share an imprint of 
changes driven by events and processes in recent times, overlying the product of long-term processes that shape the living soils of Earth's surface.

\section{The Forest and Rangeland Soils of the United States}

Forest soils are a vital component of most, if not all, of the United States. Although forests occupy only about one-third of the nation's land area, they provide $80 \%$ of the nation's surface freshwater (Sedell et al. 2000). Forest and rangeland soils were degraded across the United States at an alarming rate in the 1700s and 1800s, primarily due to land conversion to agriculture and unsustainable tree harvesting and grazing practices. Later, particularly in the East, many agricultural lands were abandoned and forests returned. The US forest land base has remained relatively stable at around 160 million ha since the $1920 \mathrm{~s}$, despite population growth. Accommodation of a growing population is expected to reduce cropland, pasture, range, and forest area in the future, largely as a result of urbanization and other land development (USDA FS 2012). Urban land area increased 44\% between 1990 and 2010 (USDA FS 2016). The Southeast is expected to have the greatest loss of forest, ranging from 4.0 to 8.5 million ha between 2010 and 2060 or roughly $4-8 \%$ of the region's 2007 forest land base (USDA FS 2012). Appendix A explores forest and rangeland soils in greater depth by US region, state, territory, or affiliated island.

Today, forest and rangeland soils are vulnerable to degradation from several additional threats. Both natural and human-caused disturbances have degraded forest and range- land soils across the United States, with various environmental changes, overgrazing, overharvesting, severe wildfire, and invasive plant and animal species as the greatest concerns. Effects on soil health are expected to be more severe when two or more of these disturbances or stressors interact with each other. Additionally, in the Eastern United States, acid deposition remains an important concern for both soil acidification and nitrogen $(\mathrm{N})$ enrichment, including potential changes in species composition and leaching of $\mathrm{N}$ into aquatic ecosystems. Even though the implementation of clean air laws and standards has dramatically decreased acid deposition, in many cases soil recovery has been slow (Likens et al. 1996). Any deleterious effects on forest and rangeland soils will be magnified or accelerated by changes in the climate. But there is great uncertainty about the extent and nature of these effects as impacts will depend on the magnitude of temperature and precipitation changes and the frequency of extreme events.

Changes in forest soils may enhance or degrade their ability to support trees and other life. For example, forest management may add substantial amounts of fertilizer to about 400,000 ha of pine forests each year in the Southeast, boosting both growth and profits from forest lands (Albaugh et al. 2018).

\section{Soil Variability}

The ability of soils to grow trees typically varies by twofold or more across local landscapes (Fig. 1.1) and across forested regions (Fig. 4.7). Returning to our local example, about one-quarter of the Sumter National Forest can grow

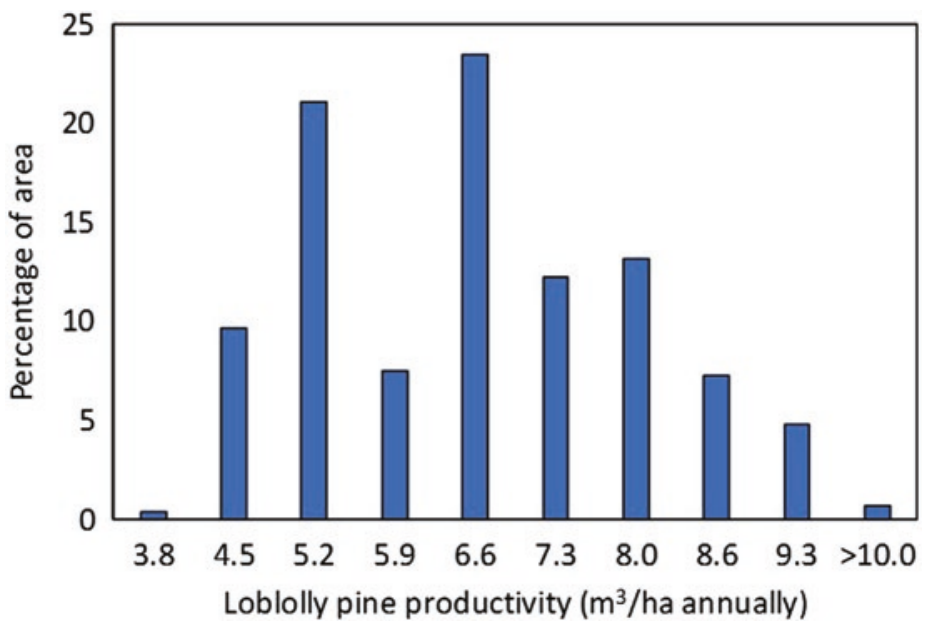

Fig. 1.1 Percentage of a 100,000 ha portion of the Sumter National Forest (including the Calhoun Experimental Forest) supporting various levels of loblolly pine annual productivity. The ability of soils to grow loblolly pine trees varies greatly across this area, owing to the differences in soil parent material, erosion history, landscape position, and the biogeochemical cycles that support tree nutrition (data from Soil Survey Staff n.d.). Silvicultural treatments and selected tree genotypes have more than doubled levels of inherent soil productivity for pine production in the Southeast 
only $5 \mathrm{~m}^{3} \mathrm{ha}^{-1}$ annually or less, whereas another one-quarter can grow more than $8 \mathrm{~m}^{3} \mathrm{ha}^{-1}$ annually (Fig. 1.1). Most forest soils can grow trees even more rapidly if amended with fertilizers. The climate is relatively uniform across local areas, but differences in soil textures (especially the amount of clay), drainage, and slope position cause large differences in the ability of soils to retain water between storms. The ability of soils to supply nutrients for tree growth is probably more important than differences in water holding capacity. For example, the Southeast Tree Research and Education Site (SETRES, a long-standing collaboration between the Southern Research Station, North Carolina State University, Duke University, and the North Carolina State Forest Nutrition cooperative member companies) demonstrated that irrigating a loblolly pine (Pinus taeda) stand on a soil with low water holding capacity might increase growth by $25 \%$, but fertilizing the stand would double growth (Albaugh et al. 2004).

The variation in soil productivity across landscapes is matched by the variation caused by changes over time and in response to management activities. Forest management can increase soil productivity or degrade it. Changes in the ability of soils to support tree growth are particularly important for national forests, because the Multiple-Use SustainedYield Act of 1960 requires "coordinated management of the various resources, each with the other, without impairment of the productivity of the land" and the National Forest Management Act of 1976 requires that plans "insure research on and (based on continuous monitoring and assessment) in the field evaluation of the effects of each management system to the end that it will not produce substantial and permanent impairment of the productivity of the land." Some forest management activities, such as planting genetically selected trees and controlling competing vegetation, can lead to siz- able increases in wood production, though soils may not be greatly altered. Other activities, such as site preparation that entails soil compaction, removal of too much topsoil, or overly intense slash fires, may lower soil productivity.

\section{Legacies of Forest Soils Research}

Research in forest and rangeland soils, particularly research incorporating long-term measurements, provides important, fundamental insights into the processes that influence the ability of soils to support plant growth. The three investigations described next illustrate the kinds of insights that research can contribute to our foundational understanding of how trees and soils interact.

\section{Calhoun Experimental Forest, Sumter National Forest, South Carolina}

The highly eroded landscapes of the Sumter National Forest were restored to productive forests through intensive planting, natural regeneration, and conservation work by the Civilian Conservation Corps - all benefiting from a strong research component. Lou Metz was one of the early directors of the Calhoun Experimental Forest charged with restoring forest, land, and water resources following some of the most severely damaging agricultural impacts in the United States (Metz 1958). Carol Wells, a scientist with the USDA Forest Service (hereafter, Forest Service), developed a detailed soil sampling protocol in an old cotton field experimentally planted with loblolly pine in the Calhoun Experimental Forest (Fig. 1.2). Wells returned about every 5 years to examine how the trees drove changes in the soil.
Fig. 1.2 Shortly before this photo was taken, this former cotton field in the Sumter National Forest was planted with loblolly pine from seed collected across the entire Southeastern United States. (Photo credit: USDA Forest Service, circa 1958)

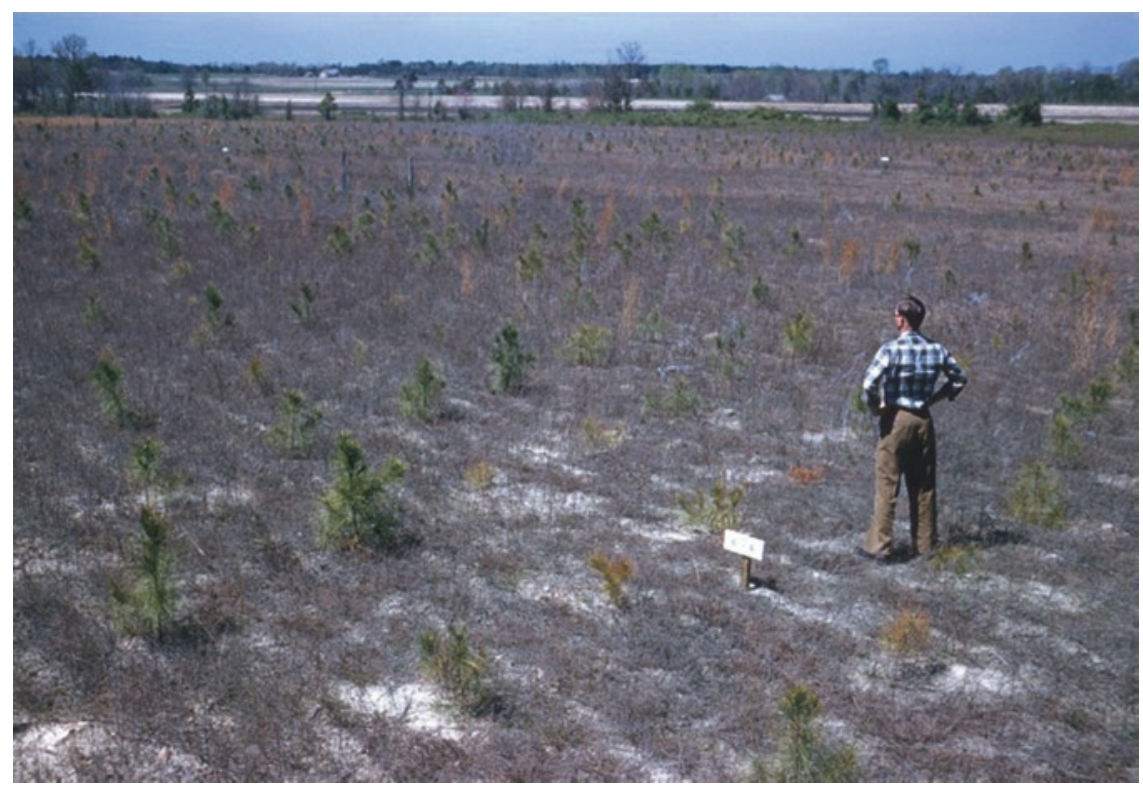


The timeframe of the development of forests and soils may extend beyond the career of individual scientists, and eventually Wells turned over his experiment to Dan Richter and colleagues. They continued this work and expanded it after Wells retired in about 1990. One dramatic long-term effect that the trees had on the soil was the restoration of the important $\mathrm{O}$ horizon, made up of fresh litter and decomposing organic matter (Richter and Markewitz 2001; Richter et al. 1999). The rate of carbon (C) accumulation in the $O$ horizon was rapid, about one-quarter of the rate of accumulation in the trees themselves. In contrast, the A and B horizons of the mineral soils showed no overall change in the storage of $\mathrm{C}$ and were rapidly depleted of $\mathrm{N}$, phosphorus, and calcium, nutrients that the regenerating trees required in large amounts. The lack of net change in organic $\mathrm{C}$ might indicate that little activity occurred in the mineral soil, but investigations using $\mathrm{C}$ isotopes showed that the mineral soil $\mathrm{C}$ was actually highly dynamic: High rates of $\mathrm{C}$ input were matched by high rates of decomposition and loss.

\section{Sylvania Wilderness, Ottawa National Forest, Michigan}

The long-term development of soils depends strongly on the influences of trees, but the Sylvania Wilderness demonstrates how soil formation can be very different under the influence of different species of trees. The old-growth forests of the Upper Peninsula of Michigan, where the Ottawa National Forest is located, often contain a mosaic of patches of eastern hemlock (Tsuga canadensis) and northern hardwoods, with vegetation changing from one type to the other at distances of 50-100 m (Frelich et al. 1993). The boundaries between these conifer and hardwood patches in the Sylvania Wilderness have been remarkably stable at timeframes of 100 to more than 1000 years, especially considering the minimal differences in topography or soil drainage between patches. Major differences in the rates of nutrient cycling may be the most plausible explanations. Species such as sugar maple (Acer saccharum) foster higher rates of soil $\mathrm{N}$ turnover, whereas hemlock litter decomposes gradually and slows down $\mathrm{N}$ turnover. The hardwood species thrive with higher soil $\mathrm{N}$ supplies, while hemlock is adept at tolerating low soil N. After generations of trees have shaped the soils, the soils influence which trees will be most successful. Yet these long-term patterns are likely to change in the near future. Invasions of exotic earthworms (suborder Lumbricina) into the Sylvania Wilderness (and many other forests of North America) are drastically altering soils, N supplies, and the successful establishment of trees (Hendrix and Bohlen 2002). These effects show how soil-forming factors are dynamic_-indeed, constantly changing_and, in our world today, most certainly include human-related interactions (Richter and Yaalon 2012).

\section{Long-Term Soil Productivity Program, United States and Western Canada}

One of the most valuable ongoing programs of wildland soils research is the Long-Term Soil Productivity (LTSP) program (Mushinski et al. 2017; Powers et al. 2005). This coordinated network of over 100 sites (Fig. 1.3) was initiated in 1991 in response to concerns that the removal of organic matter and
Fig. 1.3 The Long-Term Soil Productivity program has been following the effects of forest management on soils for three decades at more than 100 locations across North America. (Source: USDA FS 2018)

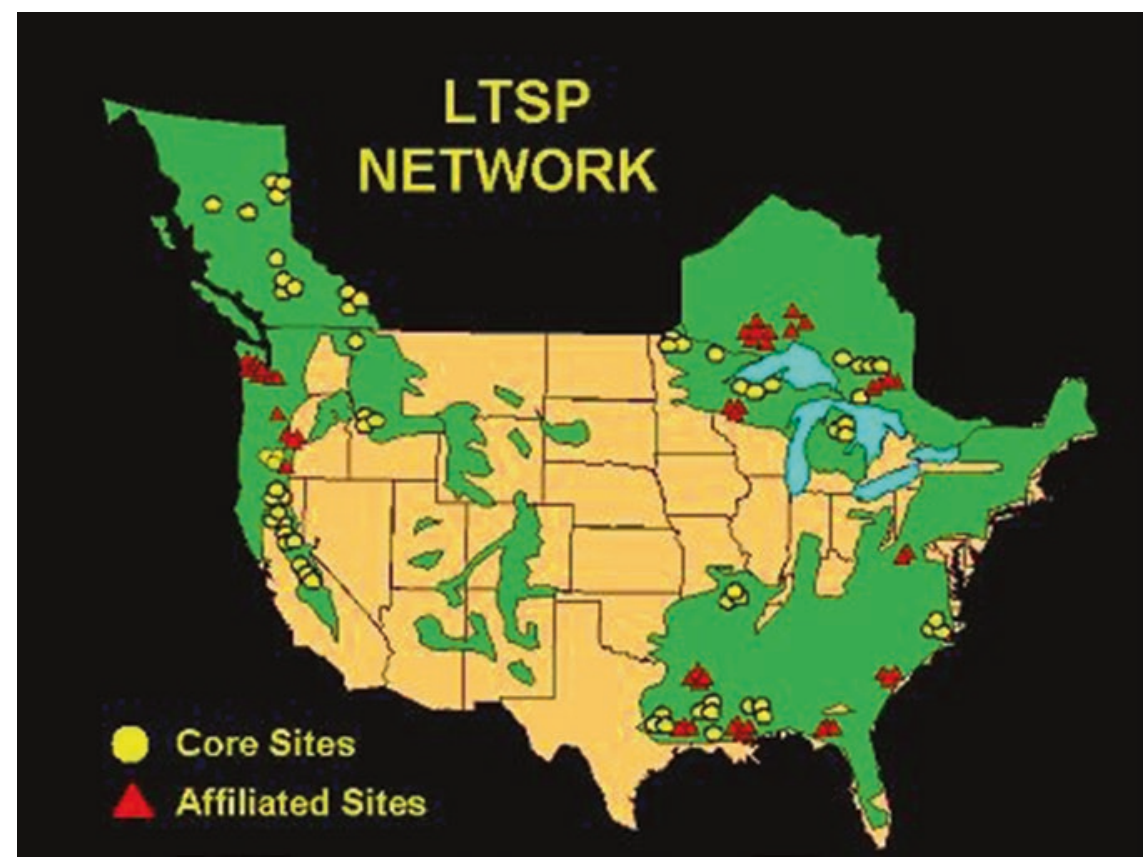


compaction of soils in forest harvests could alter soil fertility and site productivity. Two important insights from this network of experiments are as follows: (1) The effects of biomass removal on soil productivity depend strongly on the type of biomass removed. The removal of organic matter in the form of branches and logging slash generally did not affect the growth of regenerating forests, but removal of the organic matter from the $\mathrm{O}$ horizon frequently reduced site productivity. (2) The effects of harvesting vary substantially across sites, at both local and regional scales. Lessons learned from a single experimental forest site may have limited value for explaining forest and soil dynamics across the broader diversity of conditions on forested landscapes.

The LTSP approach is effective because it provides a framework for calculating average responses and variations around averages and for identifying the site factors that best explain the variation. As noted later, a large network such as the LTSP program takes great dedication from the scientists and forest managers who work on each site and sustained financial support from core institutions.

\section{Monitoring to Detect Changes in Soil}

Forests and the soils that support them are remarkably dynamic. Before colonial settlement, most forested sites in North America had been covered by forests for millennia. Any single forest might be young or old, depending on the time elapsed since stand-replacing events such as fires and hurricanes. A similar story applies to forest soils. Soils that developed through interactions with trees have fundamental characteristics (such as the presence of an $\mathrm{O}$ horizon above the A horizon) that persist across generations of trees. Longterm spatial patterns of soils are influenced by changes over shorter time periods, in response to changes in the species of trees, the time since stand-replacing events, land use history, and ongoing management activities. The turnover time for $\mathrm{C}$ in upper soil horizons averages about 15-300 years (Schmidt et al. 2011), not much different from the lifespan of trees.

We know that individual soils can change substantially over a period of years and decades, but we do not yet have the ability to describe the local changes that may be expected across landscapes and regions. Some countries have major programs devoted to determining rates of change in forest soils and identifying the factors that account for differences in rates of change. For example, Germany has a system of over 1800 plots that have been sampled every decade since the 1980s (Grüneberg et al. 2014). Sampling is 10 times more intensive in Sweden, where more than 20,000 locations are sampled every 10 years (Nilsson et al. 2015).

Considerable data are collected to document the state of soil resources in the United States. The primary source for soil information is the Soil Survey Geographic (SSURGO) database, which is accessible through the USDA Natural Resources Conservation Service (USDA NRCS) Web Soil Survey. This database contains hundreds of estimated properties for soil landscapes that cover more than $90 \%$ of the continental United States (1:24,000 spatial scale). The State Soil Geographic (STATSGO2) database, also distributed through the Web Soil Survey, provides a smaller set of estimated properties for the entire country at a 1:250,000 scale. The spatial resolution of the chemical data in SSURGO is sufficient for large, homogeneous landscapes, but in variable terrain with multiple soil parent materials (much of which is under forest and rangeland cover), this dataset is limited.

The National Cooperative Soil Survey (NCSS) Soil Characterization database, maintained by the USDA NRCS, contains measured data on over 1000 soil properties obtained from over 63,000 sites throughout the United States and the world. The NCSS also contains calculated data on many other soil properties. All of these datasets are based on consistent, well-documented standards and specifications.

The Forest Service's Forest Inventory Analysis (FIA) program produces a survey of the state of United States forests, including forest soils, and reports on issues such as landcover change, $\mathrm{C}$ sequestration, and effects of pollutants and fires. The survey includes approximately 125,000 plots for core data collection, of which about 7800 are sampled intensively and include forest health and soil characteristics.

Several public-private collaborations aggregate and analyze large quantities of soil data. One example is the International Soil Carbon Network (ISCN), a platform working to develop a globally integrated database of soil $\mathrm{C}$ measurements. This network partners with several Federal programs, including the interagency United States Global Change Research Program (USGCRP) and the National Science Foundation-funded National Ecological Observatory Network (NEON). Many other datasets are hosted by Federal entities such as the United States Environmental Protection Agency and the Department of Energy. Despite all of these efforts, however, many existing datasets lack the requisite resolution for effective policy and soil management decisions. Many higher-resolution datasets are regional and lack integration into national databases. Thus, the United States lacks a single clearinghouse for soil data or infrastructure for intercomparison of heterogeneous datasets, especially those containing data collected via different protocols and with different objectives. Aggregation and intercomparison are inherently difficult due to the wide range of soil properties, the varying degree of importance of each property depending on the location and land use or land-cover type, scale, and the different research needs for different soil management goals. 


\section{Research Challenges}

The most important challenges for research that will increase fundamental understanding of soils and sustain long-term ecosystem health are identified throughout this assessment and summarized in Chap. 10. These challenges include:

- Understanding how soils are affected by changes in precipitation patterns, air temperatures, carbon dioxide $\left(\mathrm{CO}_{2}\right)$ concentrations, atmospheric deposition of fertilizing and acidifying compounds, increasing frequency and intensity of wildfire, and urban land use change;

- Understanding the effects of invasive species including methods for tracking, mitigation, and adaptation;

- Research that can inform management practices to sustain and restore soil water holding capacity, organic matter, fertility, biotic diversity, and productivity under changing conditions; and,

- A long-term, consistent commitment of funding to support collection, analysis, and archiving of samples and the associated databases.

\section{Physical and Human Resources for Knowledge Acquisition, Integration, Analysis, and Transfer}

Finally, this report highlights the integral role of monitoring, modeling, mapping, digital databases, and human resources that underlie modern soils research. These resources are key to providing the science that can help to sustain agriculture, silviculture, grazing, abundant water, and other ecosystem services provided by forest and grassland soils. These essential resources will expand knowledge of how to protect and restore soil fertility and water holding capacity, prevent erosion, build and protect soil organic matter, and promote the soil invertebrates and microorganisms driving soil health-promoting chemical and physical processes. Some key existing networks and programs have already been mentioned. Additional resources are mentioned in Chaps. 2, 3, 4, 5, 6, 7, 8 and 9, and all are summarized in Appendix B. These resources and institutions provide the means and capacity to:

- Monitor, model, map, store, and access data networks supporting soils research and management;

- Provide training and opportunities for the next generation of scientists; and,

- Communicate findings and conduct outreach for the benefit of local communities; urban populations; rural landowners; growers; and local, regional, and Federal policymakers and decision-makers.

\section{Key Findings}

- Changes in forest soils across the United States are driven by events and processes in recent times, overlying the long-term processes that shape the living soils of Earth's surface. Long-term soil spatial patterns are influenced by short-term changes in tree species, time since standreplacing events, land use history, and ongoing management activities.

- Today's forests occupy only about one-third of the nation's land area but provide $80 \%$ of the nation's surface freshwater.

- Historically over 50 million ha of eastern United States forests were converted to primarily agricultural uses. Much of this has reverted to forest since World War I, but about 400,000 forested ha annually are now being converted to urban or suburban purposes to accommodate urban and suburban growth.

- Research in forest and rangeland soils, particularly research networks that encompass a broad range of site conditions and long-term measurements, provides fundamental insights into the processes that influence the ability of soils to support plant growth.

- The turnover time for $\mathrm{C}$ in upper soil horizons averages about 15-300 years, not much different from the lifespan of trees. Removing soil organic matter significantly reduces soil $\mathrm{C}$, whereas removing tree branches and logging slash has comparatively little effect.

- Key soils databases in the United States include SSURGO, STATSGO2, NCSS, LTSP, and FIA. Collaborations that aggregate and analyze large quantities of soils data include the ISCN, USGCRP, and NEON. (See also Appendix B.)

\section{Key Information Needs}

- A single national clearinghouse needs to be created and maintained for soil data or infrastructure for intercomparison of heterogeneous datasets, especially those containing data collected via different protocols and with different objectives and higher-resolution regional datasets. Data with higher resolution than is generally currently available are needed to more effectively inform policy and soil management decisions.

- The ability to describe expected local changes across landscapes and regions would require intensification of current soil monitoring networks as individual soils can change substantially over a period of years and decades. Sweden and Germany offer good models for systematic monitoring. The FIA soils indicator currently monitors about 7800 sites. 
- Understanding how human-caused changes affect soil health and productivity will be of key importance to managing soils in the future. Specific information needs regarding soil water, nutrients, and biota, as well as wetland soils and urban soils, are detailed in Chaps. 3, 4, 5, 6 and 7 , respectively.

\section{Literature Cited}

Albaugh TJ, Allen HL, Dougherty PM, Johnsen KH (2004) Long term responses of loblolly pine to optimal nutrient and water resource availability. For Ecol Manag 192(1):3-19

Albaugh TJ, Fox TR, Cook RL et al (2018) Forest fertilizer applications in the southeastern United States from 1969 to 2016. For Sci. https://doi.org/10.1093/forsci/fxy058

Frelich LE, Calcote RR, Davis MB, Pastor J (1993) Patch formation and maintenance in an old-growth hemlock-hardwood forest. Ecology 74(2):513-527

Gallman RE, Weiss TJ (1969) The service industries in the nineteenth century. In: Fuchs VR (ed) Production and productivity in the service industries. Columbia University Press, New York, pp 287-352

Grüneberg E, Ziche D, Wellbrook N (2014) Organic carbon stocks and sequestration rates of forest soils in Germany. Glob Chang Biol 20:2644-2662

Hendrix PF, Bohlen PJ (2002) Exotic earthworm invasions in North America: ecological and policy implications. Bioscience 52(9):801-811

Likens GE, Driscoll CT, Buso DC (1996) Long-term effects of acid rain: response and recovery of a forest ecosystem. Science 272(5259):244-246

Metz LJ (1958) The Calhoun Experimental Forest. U.S. Department of Agriculture, Forest Service, Southeastern Forest Experiment Station, Asheville, $24 \mathrm{p}$

Multiple-Use Sustained-Yield Act of 1960; Act of June 12, 1960; 16 U.S.C. 528 et seq

Mushinski RM, Boutton TW, Scott DA (2017) Decadal-scale changes in forest soil carbon and nitrogen storage are influenced by organic matter removal during timber harvest. J Geophys Res Biogeo 122(4):846-862
National Forest Management Act of 1976; Act of October 22, 1976; 16 U.S.C. 1600

Nilsson T, Stendahl J, Löfgren O (2015) Markförhållanden i svensk skogsmark-data från Markinventeringen 1993-2002. Rapport 19, Institutionen för mark och miljö, Sveriges lantbruksuniversitet, Uppsala. In Swedish only; for information in English, see: https://www.slu.se/en/Collaborative-Centres-and-Projects/ Swedish-Forest-Soil-Inventory/

Powers RF, Scott DA, Sanchez FG et al (2005) The North American Long-Term Soil Productivity experiment: findings from the first decade of research. For Ecol Manag 220(1-3):31-50

Richter DD, Markewitz D (2001) Understanding soil change: soil sustainability over millennia, centuries, and decades. Cambridge University Press, New York, $255 \mathrm{p}$

deB Richter D, Yaalon DH (2012) "The changing model of soil" revisited. Soil Sci Soc Am J 76(3):766-778

Richter DD, Markewitz D, Trumbore SE, Wells CG (1999) Rapid accumulation and turnover of soil carbon in a re-establishing forest. Nature 400:56-58

Schmidt MW, Torn MS, Abiven S et al (2011) Persistence of soil organic matter as an ecosystem property. Nature 478:49-56

Sedell J, Sharpe M, Apple DD et al (2000) Water and the Forest Service. FS-660. U.S. Department of Agriculture, Forest Service, Policy Analysis, Washington, DC, $26 \mathrm{p}$

Soil Survey Staff (n.d.) Web soil survey. U.S. Department of Agriculture, Natural Resources Conservation Service. https://websoilsurvey. nrcs.usda.gov/app/WebSoilSurvey.aspx. Accessed November 20, 2017

USDA Forest Service [USDA FS] (2012) Future of America's Forest and Rangelands: Forest Service 2010 resources planning act assessment. General Technical Report WO-87. Washington, DC, 198 p

USDA Forest Service [USDA FS] (2016) Future of America's Forests and Rangelands: update to the 2010 Resources Planning Act Assessment. General Technical Report WO-GTR-94. Washington, DC, $250 \mathrm{p}$

USDA Forest Service [USDA FS] (2018) Research topics: Forest management. The Long-Term Soil Productivity Experiment. U.S. Department of Agriculture, Forest Service, Pacific Southwest Research Station, Albany. https://www.fs.fed.us/psw/topics/forest_ mgmt/ltsp/. Accessed April 16, 2019

U.S. Energy Information Administration (2011) History of energy consumption in the United States, 1775-2009. https://www.eia.gov/ todayinenergy/detail.php?id=10. Accessed November 20, 2017

Open Access This chapter is licensed under the terms of the Creative Commons Attribution 4.0 International License (http://creativecommons. org/licenses/by/4.0/), which permits use, sharing, adaptation, distribution and reproduction in any medium or format, as long as you give appropriate credit to the original author(s) and the source, provide a link to the Creative Commons license and indicate if changes were made.

The images or other third party material in this chapter are included in the chapter's Creative Commons license, unless indicated otherwise in a credit line to the material. If material is not included in the chapter's Creative Commons license and your intended use is not permitted by statutory regulation or exceeds the permitted use, you will need to obtain permission directly from the copyright holder. 